\title{
Prevalence and determinants of anemia amongst HIV positive pregnant women in a tertiary Hospital in Nigeria
}

\author{
Innocent O. Eze ${ }^{1}$, Clara U. Innoeze ${ }^{2}$, Malachy E. Ayogu ${ }^{3 *}$, Stephen C. Eze
}

\author{
${ }^{1}$ Department of Obstetrics and Gynecology, Nigerian Navy Reference Hospital, Calabar, Nigeria \\ ${ }^{2}$ Department of Clinical Psychology, Imo State University, Owerri, Nigeria \\ ${ }^{3}$ Department of Obstetrics and Gynecology, University of Abuja Teaching Hospital, Gwagwalada Abuja, Nigeria \\ ${ }^{4}$ Department of Obstetrics and Gynecology, Federal Medical Centre Owerri, Nigeria
}

Received: 09 September 2020

Revised: 13 October 2020

Accepted: 17 October 2020

\section{*Correspondence:}

Dr. Malachy E Ayogu,

E-mail: emekamalachy01@gmail.com

Copyright: $\odot$ the author(s), publisher and licensee Medip Academy. This is an open-access article distributed under the terms of the Creative Commons Attribution Non-Commercial License, which permits unrestricted non-commercial use, distribution, and reproduction in any medium, provided the original work is properly cited.

\begin{abstract}
Background: In pregnancy, anemia is associated with increased risk of both maternal and fetal morbidity and mortality especially in HIV situation. To determine the prevalence and determinants of anemia in HIV positive compared to HIV negative women.

Methods: This was a cross sectional study carried out from June 2016 to December 2017 amongst pregnant women who presented to the antenatal clinic. Information on socio-demographic variables and laboratory test to determine the hemoglobin levels and CD4 count (for the HIV positive women) were carried out. A total of 350 subjects with equal number of HIV positive and HIV negative pregnant women were recruited. Variables were compared between the two groups using software package for social sciences version $20 . \mathrm{P}$ values $<0.05$ at $95 \%$ confidence interval are considered statistically significant.

Results: The mean age for HIV positive and negative were $31.54 \pm 4.1$ and 29.03 respectively while, mean gestational age at booking for HIV positive and negative were $20.41 \pm 8.61$ and $22.37 \pm 7.4$ weeks respectively. The HIV positive group had a mean parity of $2.02 \pm 1.5$, and $2.56 \pm 1.2$ was that of the HIV negative group. The mean hemoglobin statuses at booking were $9.92 \pm 1.8 \mathrm{~g} / \mathrm{dl}$ and $10.6 \pm 1.1 \mathrm{~g} / \mathrm{df}$ HIV positive and HIV negative women respectively. The mean CD4+ at booking for HIV positive group was $478 \pm 251$ per microliter. The overall prevalence of anemia irrespective of HIV status was $36.6 \%$. The prevalence of anemia in HIV positive and negative women were $44.6 \%$ and $28.6 \%$ respectively. There was statistically significant relationship between anemia and HIV status ( $\mathrm{p}=0.002)$.

Conclusions: There was inverse relationship between CD4+ count and anemia. Low CD4+ count and non-use of HAART at booking were important determinants of anemia among the HIV.
\end{abstract}

Keywords: Anemia, CD4+, Determinants, HIV, Prevalence, Nigeria

\section{INTRODUCTION}

Human immunodeficiency virus (HIV) infection is frequently associated with hematological abnormalities such as anaemia. ${ }^{1}$ In most of the anemia prevalence studies, where HIV infection was evaluated as possible risk factor, HIV infection was independent and strong risk factor for anaemia. ${ }^{1,2}$ Anaemia in pregnancy has remained one of the public health challenges to safe motherhood in developing parts of Africa despite the considerable improvement in health-care-delivery services. ${ }^{2}$ The maternal and fetal morbidity and mortality associated with anemia in pregnancy especially in the HIV setting have been long established. ${ }^{1,2}$ 
Maternal complications of anemia include poor weight gain, decreased immune response and work capacity, preterm labor, dysfunctional labor, puerperal sepsis, subinvolution of uterus, lactation failure. ${ }^{2-4}$ Severe anemia in pregnancy may result in circulatory changes that are associated with increased risk of heart failure. ${ }^{2}$ During labor, women with severe anemia are less able to cope with even moderate blood loss resulting in post-partum hemorrhage which is among the leading causes of maternal mortality in developing Africa., ${ }^{2,3}$ For the fetus, severe maternal anemia may result in intrauterine growth restriction, low birth weight, poor APGAR score and stillbirth. ${ }^{2,4,5}$

In Sub-saharan Africa, causes of anemia in pregnancy are multifactorial including dietary deficiency of iron, vitamin B12, and folate. Others include malaria, acute and chronic infections and haemoglobinopathies. ${ }^{6}$

HIV/AIDS, in the category of chronic infections, is regarded as strong risk factor for anemia in pregnancy. ${ }^{7}$

Of the world's estimated 33.3 million people infected with HIV as at 2009, 68\% (22.5 million) resides in subSaharan Africa. ${ }^{8}$

A relationship between HIV sero-positivity and decreased hemoglobin $(\mathrm{Hb})$ concentration in pregnancy has been suggested in some studies, and inclusion of HIV screening in differential diagnosis of anemia is recomended. ${ }^{2}$ The etiology of anemia in HIV infection may include low production of red blood cells, increased red cell destruction, or ineffective red blood cell production; 4 laboratory features are compatible with anemia of chronic disease with low reticulocyte count, normocytic and normochromic red blood cells with iron normal stores and cytokine mediated poor erythropoietin response. ${ }^{9}$ The prevalence of anemia in HIV Infection is about $30 \%$ in patients with asymptomatic HIV and ranges from $75-80 \%$ in those with clinical AIDS. ${ }^{10}$

Studies suggest that use of highly active antiretroviral therapy (HAART) is associated with an increase in hemoglobin concentrations and thus decrease in prevalence of anemia. ${ }^{2,11}$

It has been noted that, in HIV patients, sufficient treatment of anemia is not always considered in developing countries, as most notice is given to HIV infection and frequent complications such as opportunistic infections. ${ }^{2}$ The world health organization (WHO) defined anemia in pregnancy as hemoglobin concentration less than $11.0 \mathrm{~g} / \mathrm{dl}^{12}$ (The hemodynamic changes in pregnancy that involve a higher physiological increase in plasma volume relative to red cell mass create a physiological anemia of pregnancy; hence cut-off point for anemia in pregnancy is slightly lower than that of the general population). ${ }^{6}$ Moderate anemia is defined as hemoglobin concentration greater than or equal to 7.0 $\mathrm{g} / \mathrm{dl}$ but less than $11 \mathrm{~g} / \mathrm{dl}$, and severe anemia as hemoglobin concentration of less than $7.0 \mathrm{~g} / \mathrm{dl} .{ }^{12}$

For practical purposes, in our environment, most pregnant women "do very well", and pregnancy outcome is good (all things being equal) with estimated hemoglobin concentration of $10 \mathrm{~g} / \mathrm{dl}$ and above. ${ }^{13}$ This relative low hemoglobin concentration may not be unconnected to the high prevalence of the unfortunate "trios" of poverty, ignorance and disease (all being indirect causes of anemia) resulting in low baseline hemoglobin making most "healthy" African women fall below the WHO cut- off for anemia. Hence, in most parts of Africa, hemoglobin level of less than $10 \mathrm{~g} / \mathrm{dl}$ is used by many clinicians as indication of anemia in pregnancy. ${ }^{13}$ Lawson was among the pioneers of this thought. ${ }^{14,15}$ It has, however, been advised that the WHO definition should be applied for diagnosing anemia in the developing countries. ${ }^{16}$

Although the WHO cut off $[\mathrm{Hb}<11 \mathrm{~g} / \mathrm{dl}]$ for anemia in pregnancy is advocated as standard, a cut of $(\mathrm{Hb}<10 \mathrm{~g} / \mathrm{dl})$ for anemia was used in this study to make it more relevant in our environment as advocated by popular scholars.

Some studies have shown significantly higher prevalence of anemia among HIV positive pregnant women than among their negative counterparts. ${ }^{1,2}$ The prevalence varies widely from studies carried in different geopolitical zones of the country. ${ }^{17-21}$ No such studies, to the author's best knowledge, had been done in the in our center before. It was therefore important to assess and document the prevalence of anemia, and the relationship of these variables to anemia in HIV positive pregnant women. It is therefore, the objective of this study to add to the existing literature on the ways to inform and improve better management of this condition.

\section{METHODS}

\section{Study design}

It was a clinic-based cross- sectional study

\section{Study location}

The study area was in federal medical centre (FMC) Owerri which is a tertiary health institution situated in Owerri, the capital city of Imo State, Nigeria. The institution has an established Obstetrics and Gynecology Department with PMTCT program supported by Center for clinical care and clinical research of nigeria (CCCRN) project.

\section{Study period}

This was carried out from June 2016 to December 2017 


\section{Selection criteria}

Consecutive HIV positive and negative pregnant women who presented for antenatal care at the hospital that gave consent to participate in the study were recruited until the sample size was reached, however, HIV positive/negative pregnant women with sickle cell anemia and other known hemoglobinopathies, HIV positive/negative pregnant women with known chronic organ (kidney, liver, heart) diseases, malignancies or parasitic infestations, HIV positive/negative pregnant women who had blood transfusion in the past three months and HIV positive/negative pregnant women who did not want to participate in the study were excluded

\section{Sample size determination}

The sample size was determined using the following formula.

$\mathrm{N}=\frac{\mathrm{Z}^{2} \mathrm{Pq}}{\mathrm{d}^{2}}$

Where, $\mathrm{N}=$ the desired sample size

$\mathrm{Z}=$ the standard normal deviation usually set at 1.96 , corresponding to $95 \%(0.95)$ confidence limit read from standardized distribution table.

$\mathrm{P}=$ Estimated prevalence was $11.5 \%$ (HIV antibody seroprevalence among pregnant women at booking in Orlu, Southeast Nigeria) ${ }^{17}$

$\mathrm{Q}=1-\mathrm{P}$

$\mathrm{d}=$ the degree of accuracy, usually set at $5 \%(0.05)$

For this study

$\mathrm{N}=\frac{1.962 \times 0.115 \times 0.885}{(0.05) 2}=156.40$ $(0.05) 2$

To take care of the defect due to study design and increase the power of study, the minimum sample size was rounded off to 175 . Same number of HIV negative pregnant women were included making a total of 350 .

The procedures were explained to all subjects and a written consent obtained from them. One hundred and seventy-five (175) HIV positive pregnant women, and equal number of HIV negative pregnant women (controls), making a total of 350 subjects were studied and they were guided to fill out questionnaire on biodata. Social classes were assigned to the women using partner's occupation and educational status of the women according the scoring system designed by Olusanya et al for Nigeria and other African countries. ${ }^{22}$ Data were collected from the questionnaire and the laboratory. It was done in collaboration with the midwives/nurses who were trained in voluntary counseling and testing (VCT) and the laboratory staff of the hospital and center for clinical care and clinical research of Nigeria (CCCRN) project. The laboratory investigations were done at the CCCRN laboratory of the hospital. Other research assistants including nurses, resident doctors and laboratory staff were equally trained to participate in the study.

Investigations and drugs were taken care of by the CCCRN project in the institution. Pregnant women who presented to the antenatal clinic for booking routinely had voluntary counseling and testing using the opt-out technique. Laboratory staff made use of serial algorithm using Determine and Stat-pak (and Unigold as tiebreaker where necessary) to screen HIV status of the women. enzyme-linked immunosorbent essay (ELIZA) was for confirmation of the newly diagnosed women. Confirmed HIV positive pregnant women from the screening who met the inclusion criteria were enrolled for the study. Pregnant HIV positive women who presented to the antenatal clinic for booking with the evidence of their status were also included. HIV negative women attending the antenatal clinic who fulfilled the inclusion criteria served as controls.

History was taken and physical examination done for every patient to rule out confounding factors for those who were included in the study. Fecal and blood sample collection and analysis were also carried out on them. Confirmed positive cases of parasitic infestations and hemoglobinopathies were recorded but excluded from study. Given the multi-factorial nature of anemia, the rationale was to rule out anemia associated with these conditions.

Routine investigations done for all the pregnant women were also done for these patients. These investigations included: hemoglobin $(\mathrm{Hb})$ concentration, blood grouping and rhesus blood typing, hemoglobin genotyping, venereal disease research laboratory (VDRL) test and urinalysis. Additional investigation requested for HIV positive women included white cell (WBC) count and differentials, the blood film, CD4+count, liver function test (LFT) and stool microscopy. Those with severe liver and/or kidney function derangement were excluded from the study.

Hemoglobin $(\mathrm{Hb})$ concentration was used to determine level of anemia because of its reliability, relatively easy and inexpensive and is the most reliable indicator of anemia. Further, $\mathrm{Hb}$ concentration is considered the most reliable indicator of anemia at the population level. ${ }^{5}$

The researcher and the assistants collected blood samples with a 5mililitre plastic syringe from a prominent vein in the forearm of participants after applying tourniquet distal to the collection point which is cleaned with cotton wool soaked in methylated spirit before collection. About 3 mililitre of blood sample was emptied from the syringe (after removing the needle) in an ethylene diaminetetra 
acetic acid (EDTA) plastic containers and sent to the CCCRN laboratory for analysis. The hemoglobin estimation was done by a power-operated quality controlled 3-part differential auto analyzer, sysmex KX$21 \mathrm{~N}$ (made in Germany). The machine is known to have close to $100 \%$ sensitivity and specificity. It was manned by competent laboratory personnel, and the researcher was trained to participate in sample analysis. The CD4+ count was carried out by a power-operated qualitycontrolled cy flow counter 1 (made in Germany) with close to $100 \%$ accuracy, and manned by competent personnel with participation of the researcher.

Although the WHO cut off $[\mathrm{Hb}<11 \mathrm{~g} / \mathrm{dl}]$ for anemia in pregnancy is advocated as standard, a cut of $(\mathrm{Hb}<10 \mathrm{~g} / \mathrm{dl})$ for anemia was used in this study to make it more relevant in our environment as advocated by popular scholars.

\section{Ethical consideration}

Before the study commenced an initial proposal was presented to the research and ethical committee of the institution for approval. Informed consent was obtained from the subjects before enlisting them in the study. The participants retained absolute right and freedom to decline or withdraw from participating from the study at any time with no consequences to them. They were assured that opting out would not compromise the quality of care they received from the antenatal clinic. The study was carried out in strict confidentiality as participants and their samples were identified by initials and serial numbers on their questionnaires, laboratory forms and specimen containers. Those that participated in the study had the advantage of early diagnosis of anemia if present and benefited from early intervention and prevention of consequences of anemia in the index pregnancy.

\section{Statistical analysis}

Data were computed and analyzed using computer software package for social sciences version 20 (SPSS, Inc. USA). Descriptive statistics (mean, standard deviation, percentages etc.) were determined for continuous variables.

Pearson chi square tests; a non-parametric inferential statistic was used to determine significant association for dichotomous variables. The following parameters were evaluated in terms of their association with hemoglobin level: demographic characteristics, CD4 count, use/duration of use of highly active anti-retroviral therapy (HAART). The results were presented using tables and charts. $\mathrm{P}$ values $<0.05$ at $95 \%$ confidence interval are considered statistically significant. Correlations were determined where applicable. Determinants of interest were subjected to binary logistic regression to ascertain the statistically significant ones which were subsequently subjected to multiple logistic regressions to determine the possible risk factor (s) for anemia. Results were reported as odds ratio and correlation coefficient.

\section{RESULTS}

One hundred and seventy-five (175) HIV positive pregnant women, and equal number of HIV negative pregnant women (controls), making a total of 350 subjects were studied.

Social class and gestational age at booking were found to have significant associations with anemia but not so in a multivariate regression as shown in Tables 1 . There was a statistically significant negative correlation.

Table 1: Socio-demographic variables.

\begin{tabular}{|lll|}
\hline Parameters & $\begin{array}{l}\text { HIV } \\
\text { positive }\end{array}$ & $\begin{array}{l}\text { HIV } \\
\text { Negative }\end{array}$ \\
\hline Age (in years) & $0(0.0)$ & $10(5.7)$ \\
\hline $20-24$ & $11(6.3)$ & $32(18.3)$ \\
\hline $25-29$ & $38(21.7)$ & $40(22.9)$ \\
\hline $30-34$ & $83(47.4)$ & $83(47.8)$ \\
\hline $35-39$ & $43(24.6)$ & $10(5.7)$ \\
\hline$\geq 40$ & $175(100.0)$ & $175(100.0)$ \\
\hline Total & & \\
\hline Parity & $23(13.1)$ & $10(5.7)$ \\
\hline Primigravida & $49(28.0)$ & $10(5.7)$ \\
\hline Primipara & $95(54.3)$ & $143(81.7)$ \\
\hline Multpara & $8(4.6)$ & $12(6.9)$ \\
\hline Grandmultipara & $175(100.0)$ & $175(100.0)$ \\
\hline Total & & \\
\hline Gestational age at booking & $20(11.4)$ \\
\hline $1^{\text {st }}$ trimester & $55(31.4)$ & $94(53.7)$ \\
\hline $2^{\text {nd }}$ trimester & $80(45.7)$ & $61(34.9)$ \\
\hline $3^{\text {rd }}$ trimester & $40(22.9)$ & $175(100.0)$ \\
\hline Total & $175(100.0)$ & \\
\hline Social class & & $11(6.3)$ \\
\hline Upper & $6(3.4)$ & $68(38.9)$ \\
\hline Middle & $71(40.6)$ & $96(54.9)$ \\
\hline Lower & $98(56)$ & $175(100.0)$ \\
\hline Total & $175(100.0)$ & \\
\hline
\end{tabular}

The mean age was $31.54 \pm 4.1$ years and $29.03 \pm 5.0$ for HIV positive and negative group respectively. Mean gestational age at booking were 20.41 28 .61 weeks for HIV positive, and 22.37 \pm 7.4 weeks for HIV negative groups. The HIV positive group had a mean parity of $2.02 \pm 1.5$, and $2.56 \pm 1.2$ was that of the HIV negative group; they are shown on Table 1 . The mean hemoglobin statuses at booking among HIV positive and HIV negative pregnant women were $9.92 \pm 1.8 \mathrm{~g} / \mathrm{dl}$ and $10.6 \pm 1.1 \mathrm{~g} / \mathrm{dl}$ respectively. The mean CD4+ at booking for HIV positive group was $478 \pm 251$ per microliter. 
The overall prevalence of anemia irrespective of HIV status using the cut off points $\mathrm{Hb}<11 \mathrm{~g} / \mathrm{dl}$ and $\mathrm{Hb}<10 \mathrm{~g} / \mathrm{dl}$ were $36.6 \%$ and $65.7 \%$ respectively; anemia prevalence among HIV positive and negative using $\mathrm{Hb}<11 \mathrm{~g} / \mathrm{dl}$ as cut off point were 73.7 and $57.3 \%$ respectively and 44 and $28.1 \%$ respectively using $\mathrm{Hb}<10 \mathrm{~g} / \mathrm{dl}$ (Table 2 ).

Table 2: Anemia severity and analysis.

\begin{tabular}{|c|c|c|}
\hline Parameters & \multicolumn{2}{|l|}{ HIV positive } \\
\hline \multicolumn{3}{|c|}{ Overall anemia prevalence irrespective of HIV status } \\
\hline $\mathrm{Hb}<11 \mathrm{~g} / \mathrm{dl}$ & \multicolumn{2}{|c|}{$230(63.7 \%)$} \\
\hline $\mathrm{Hb}<10 \mathrm{~g} / \mathrm{dl}$ & \multicolumn{2}{|l|}{$128(36.6 \%)$} \\
\hline \multicolumn{3}{|c|}{ Anaemia Prevalence in HIV Positive Subjects } \\
\hline $\mathrm{Hb}<11 \mathrm{~g} / \mathrm{dl}$ & \multicolumn{2}{|c|}{$129(73.7 \%)$} \\
\hline $\mathrm{Hb}<10 \mathrm{~g} / \mathrm{dl}$ & \multicolumn{2}{|l|}{$78(44.6 \%)$} \\
\hline \multicolumn{3}{|c|}{ Anemia prevalence in HIV negative subjects } \\
\hline $\mathrm{Hb}<11 \mathrm{~g} / \mathrm{dl}$ & \multicolumn{2}{|c|}{$101(57.3 \%)$} \\
\hline $\mathrm{Hb}<10 \mathrm{~g} / \mathrm{dl}$ & \multicolumn{2}{|l|}{$50(28.1 \%)$} \\
\hline \multicolumn{3}{|c|}{ Anaemia severity and HIV status (Hares et al.) } \\
\hline Anemia/Hb & HIV positive & HIV negative \\
\hline Mild (8-10 g/dl) & $64(82.1 \%)$ & $50(100 \%)$ \\
\hline Moderate $(6.5-8 \mathrm{~g} / \mathrm{dl})$ & $4(5.1 \%)$ & $0(0 \%)$ \\
\hline Severe $(<6.5 \mathrm{~g} / \mathrm{dl})$ & $10(12 \%)$ & $0(0 \%)$ \\
\hline Total & $78(100 \%)$ & $50(100 \%)$ \\
\hline
\end{tabular}

The overall prevalence of anemia irrespective of HIV status was $36.6 \%$ as in reflected in (Figure 1). The prevalence of anemia in HIV positive pregnant women was $44.6 \%$ and $28.6 \%$ in HIV negative group. There was statistically significant relationship between anemia and HIV status ( $p=0.002)$. These were reflected in (Figure 2). Anemia prevalence was $81.7 \%$ among subjects with CD4+count of less than 200 per microliter compared to $67.8 \%$ among those with CD4+ count of 200-499 per microliter, and $63.8 \%$ in those with 500per microliter and above as shown in (Figure 2).

Most of the patients, 146 (83.4\%), were on HAART at booking (It was not ethically feasible to keep some HIV positive pregnant women from HAART for the purpose of the study, considering the already known benefit of HAART both to the baby, mother and partner in HIV positive pregnant subjects). However, a cross tabulation of hemoglobin status and duration of use of HAART did not show any statistically significant relationship $\left(\mathrm{X}^{2}=0.562, \mathrm{P}=0.454\right)$.

Social class and gestational age at booking were found to have significant associations with anemia but not so in a multivariate regression as shown in (Table 3).

There was a statistically significant negative correlation between anemia at booking and CD4+ count $(r=0.0178$, $\mathrm{p}=0.018)$.

In a multivariate regression between anemia and possible determinants, only CD4+ count was an independent risk factor as shown in (Table 4).

Table 3: Binary logistic regression analysis between anemia and variables.

\begin{tabular}{|c|c|c|c|}
\hline Variable & P value & Crude odds ratio & 95\% Confidence interval \\
\hline \multicolumn{4}{|l|}{ Parity } \\
\hline Primigravida & \multirow{2}{*}{0.07} & 1. & \multirow{2}{*}{$0.234-1.345$} \\
\hline Multigravida & & 1.64 & \\
\hline \multicolumn{4}{|l|}{ Social class } \\
\hline Upper & \multirow{3}{*}{0.002} & 1 & \\
\hline Middle & & 1.232 & $1.243-1.257$ \\
\hline Lower & & 2.543 & $1.328-2.432$ \\
\hline \multicolumn{4}{|c|}{ Gestational age at booking (weeks) } \\
\hline$<28$ & & 1 & \multirow{2}{*}{$1.023-1.487$} \\
\hline$>28$ & 0.002 & 2.78 & \\
\hline \multicolumn{4}{|l|}{ CD4+ $(/ \mu \mathrm{L})$} \\
\hline$<200$ & \multirow{2}{*}{0.001} & 3.002 & \multirow{2}{*}{$1.001-1.003$} \\
\hline$>200$ & & 1 & \\
\hline \multicolumn{4}{|l|}{ HAART } \\
\hline Yes & \multirow{2}{*}{0.004} & 1 & \multirow{2}{*}{$0.034-0.458$} \\
\hline No & & 2.759 & \\
\hline
\end{tabular}

Table 4: Multivariate analysis of anemia and identified risk factors.

\begin{tabular}{|llll|}
\hline Variable & P-value & Adjusted odds ratio & 95\% Confidence interval \\
\hline Social class & & & \\
\hline Upper & \multirow{2}{*}{0.077} & 1 & $0.243-1.257$ \\
\hline Middle & & 1.278 & $1.628-3.432$ \\
\hline Lower & & 2.124 & \\
\hline
\end{tabular}




\begin{tabular}{|c|c|c|c|}
\hline Variable & P-value & Adjusted odds ratio & 95\% Confidence interval \\
\hline \multicolumn{4}{|c|}{ Gestational age at booking (weeks) } \\
\hline$<28$ & \multirow{2}{*}{0.06} & 1 & \multirow{2}{*}{$0.523-1.987$} \\
\hline$>28$ & & 2.26 & \\
\hline \multicolumn{4}{|c|}{ CD4+ $(/ \mu \mathrm{l})$} \\
\hline$<200$ & \multirow{2}{*}{0.001} & 3.802 & \multirow{2}{*}{$1.001-1.003$} \\
\hline$>200$ & & 1 & \\
\hline \multicolumn{4}{|l|}{ HAART } \\
\hline Yes & 0.064 & 1 & \multirow{2}{*}{$0.014-2.458$} \\
\hline No & & 2.459 & \\
\hline
\end{tabular}

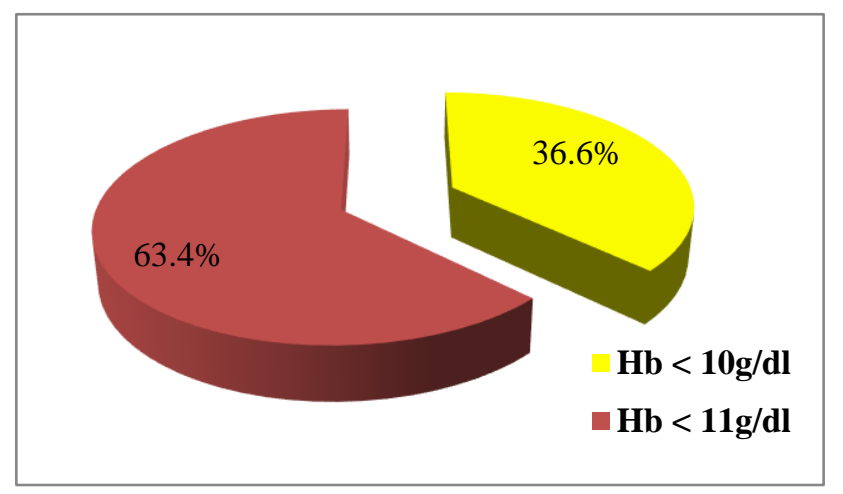

Figure 1: Overall prevalence of anemia irrespective of HIV status depending on the hemoglobin status used.

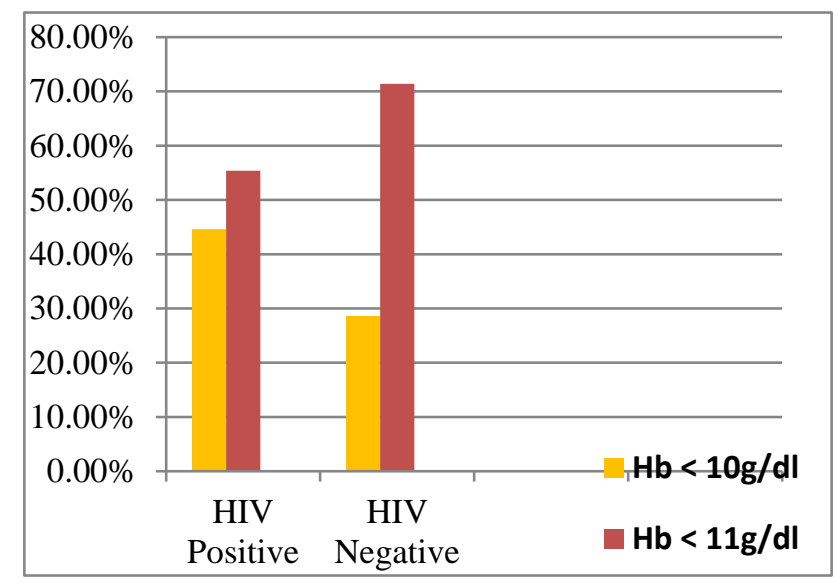

Figure 2: Retroviral status and anemia prevalence in subjects $\left(X^{2}=9.657, p=0.002\right)$.

\section{DISCUSSION}

The overall prevalence of anemia irrespective of HIV status was $36.6 \%$. This is higher compared to prevalence rate of $27.6 \%$ found in Jos Northern Nigeria, in a similar study by Ohihoinet al. ${ }^{20}$ This can partly be explained by the geographical disparity between the two study settings. Jos is located in a much higher altitude than Owerri. High altitude is said be associated with a relative compensatory higher hemoglobin concentration due to relative lower oxygen tension. ${ }^{23}$ It could also be due to differences in methodology and/or tools used in determination of anemia in the two studies. It is, however, not lower than anemia prevalence of $66.5 \%$ among HIV positive pregnant population in Orlu 17 (a neighboring town to Owerri), and $62.6 \%$ in port harcourt southern Nigeria. ${ }^{24}$ High prevalence of anemia among pregnant women in developing parts of Africa is often noted in most studies where hemoglobin concentration of $<11 \mathrm{~g} / \mathrm{dl}$ (WHO standard) was used as cut for anemia in pregnancy. This is evident in the studies above that $<11 \mathrm{~g} / \mathrm{dl}$ was used as cut off for anemia. This may not be unconnected to the high prevalence of the unfortunate "trios" of poverty, ignorance and disease (all being indirect causes of anemia) resulting in low baseline hemoglobin making most "healthy" African women fall below the WHO cutoff for anemia. Hence, in most parts of Africa, hemoglobin level of less than $10 \mathrm{~g} / \mathrm{dl}$ is used by many clinicians as indication of anemia in pregnancy. ${ }^{13}$ Lawson was among the pioneers of this thought. ${ }^{14,15}$ However it has been advised that the WHO definition should be applied for diagnosing anemia in the developing countries. ${ }^{16}$

In this study, the overall high prevalence of anemia at booking can also be partly explained by the fact that most of the subjects booked at mid trimester when the physiological dilution anemia of pregnancy is said to be at the peak. ${ }^{6}$

However, booking after 28 weeks' gestational age (GA) was associated with higher risk of anemia in HIV positive pregnant women than booking before 28 weeks GA. This is may be explained by the assumption that those who booked earlier may have a more health- seeking behaviors, and more likely to adhere to measures of anemia prevention in pregnancy.

The prevalence of anemia among HIV positive pregnant women was $44.6 \%$ and $28.6 \%$ in HIV negative group, and this was statistically significant. This is much lower compared to $75.5 \%$ prevalence rate found in Orlu, and $88.5 \%$ prevalence in Uyo (south south, Nigeria), as well as $83 \%$ reported in Tanzania it is, however, higher than $33.7 \%$ recorded in Jos, North central, Nigeria. ${ }^{17,18,23}$ The overall higher prevalence of anemia in HIV positive individuals compared to their HIV negative counterparts can be explained by changes in cytokine production (in HIV infected individuals) with subsequent effects on hematopoiesis, decreased erythropoietin 
concentration. ${ }^{2,4,26}$ Opportunistic infections such as mycobacterium avium complex and parvo virus B-19, and administration of some antiretroviral agents such as Zidovudine, Ganciglovir. ${ }^{25}$

Anemia prevalence was very high in HIV subjects with comorbid conditions. These may reflect the association of the comorbid conditions to HIV/AIDS severity. ${ }^{2,26}$

There was no significant difference in mild anemia prevalence between the HIV positive and negative subjects. Moderate and severe anemia were found only in the HIV positive group. This may imply that HIV infection is a risk factor for moderate and severe anemia.

Social class and gestational age at booking were important risk factors for anemia among HIV positive pregnant women but were not significant in multivariate analysis. These findings are similar to that in Jos among HIV positive pregnant women. ${ }^{20}$ It may be explained by the fact that gestational age at booking and social class does not influence the pathogenesis of anemia in HIV positive pregnant individuals. ${ }^{20}$

There was a statistically significant correlation between anemia in HIV positive pregnant women and CD4+ count. An inverse relationship was noted between anemia and CD4+ count. This corroborates the findings by Ferede and Wondimeneh in Northwest Ethiopia and that of Wills et al but not that of Ohihoin and associates in Jos. ${ }^{1,20,27}$ Low CD4+ count (<200 per microliter) and nonuse of HAART were found statistically significant by binary logistic regression but when both were subjected to multiple logistic regression, only low CD4+ count was significant. This is in keeping with the fact that CD4+ counts is a major disease marker in HIV positive patients as it reflects the immune status of the patients and as such used as AIDS defining immunological condition when value is less than 200 per microliter. ${ }^{2}$ Thus, it is interesting to note that the prevalence of anemia among HIV negative control $(28.6 \%)$ is lower than $44.2 \%$ found among HIV positive subjects even with CD4+ count of 500 per microliter and above. This underscores the fact that prevention of HIV infection among women of reproductive age is paramount in reducing the high prevalence of anemia among this population in our environment.

Binary logistic regression analysis between anemia and non-use of HAART was found statistically significant but not so in multiple logistic regressions. This could be explained by the fact that use of highly active antiretroviral therapy (HAART) in treatment of HIV infected patients has been shown to reduce viral load, improve $\mathrm{CD} 4+$ count, and hence reduce anemia risk in HIV positive subjects.1Anaemia was found in $75 \%$ of those who had been on HAART for less than a year compared to $72.8 \%$ in subjects that had been on HAART for one year and above but this was not statistically significant $(p=0.826)$. However, this finding can be explained by the fact that majority of the HIV positive pregnant patients studied $(83.4 \%)$ were already on HAART at booking. A more valid test of the effect of use/non-use of HAART/duration of use on anemia among HIV positive pregnant subjects could be obtained by a comparative longitudinal cohort study where statistically determined equal groups of HIV positive subjects are exposed to HAART and the other group placed on placebo are followed up to see which group develops anemia, all things being equal. This may not be ethically permissible. However, the benefits of use of HAART in suppressing viral replication, improving immunity, general health and hemoglobin status of HIV patients have been established by some studies. ${ }^{28-30}$

\section{CONCLUSION}

This study has shown a statistically significant relationship between HIV infection and anemia in pregnancy. HIV infection is significantly associated moderate and severe anemia in pregnancy. Anemia prevalence was very high in HIV subjects with comorbid conditions. There was inverse relationship between CD4+ count and anemia. Low CD4+ count and non-use of HAART at booking were important determinants of anemia among the HIV positive pregnant population. However, by multivariate analysis, only low CD4+ at booking was identified as independent determinant of anemia among HIV positive pregnant women in the study.

\section{Recommendations}

Prevention of HIV infection among women of reproductive age is paramount in reducing the prevalence of moderate and severe anemia among the pregnant women in our environment. This is because even with good management and high CD4+ count (>500/Ul), the anemia prevalence was still higher than that in HIV negative control. However, good management (including the use of HAART) of those already infected is a good practice as it certainly improves the patient immunological status (CD4+ count), reduces the comorbid conditions and the risk of anemia among HIV positive pregnant women. It is important, therefore, that the current option $\mathrm{B}+$ that recommends HAART for all HIV positive persons on diagnosis and sustained for life should be implemented by the government and donor agencies especially for women of reproductive age despite its challenges.

\section{Funding: No funding sources \\ Conflict of interest: None declared \\ Ethical approval: The study was approved by the Institutional Ethics Committee}

\section{REFERENCES}

1. Wondimeneh F. Prevalence and related factors of anemia in HAART-naive HIV positive patients at 
Gondar University Hospital, Northwest Ethiopia. Brit Med Centr Hematol. 2013;13:8.

2. Uneke CJ, Duhlinska DD, Igbinedion EB. Prevalence and Public-health Significance of HIV Infection and Anemia among PregnantWomen Attending Antenatal Clinics in South-eastern Nigeria. J Health Popul Nutr. 2007;(3):328-35

3. Shayikh SS, I, Zahid Z, Mohd MK, Sarfraz K. An Overview of Anemia in Pregnancy. J Inn Pharm and Bio Sci. 2015;2(2):144-51

4. Munyazesa E, Emile I, Mutimura E. Assessment of hematological parameters in HIV-infected and uninfected Rwandan women: Across-sectional study. Brit Med J O. 2012;2:e01600.

5. Mulambalah CS, Siamba DN, Ogutu PA, Siteti DI, Wekesa AW. Anemia in pregnancy: Prevalence and possible risk factors in Kakamega County, Kenya Sci J Pub Heal. 2014;2(3):216-22.

6. Stephen G, Mgongo M, Hashim TU, Katanga J, Stray-Perdesen B, Msuya SE. Anemia in Pregnancy: Prevalence, Risk Factors, and Adverse Perinatal Outcomes in Northern Tanzania. Hinda Anem. 2018.

7. Dairo MD, Lawoyin TO, Onadeko MO, Asekun, Olarinmoye EO, Adeniji AO. HIV as an additional risk factor for anemia in pregnancy: evidence from primary care level in Ibadan, South Western Nigeria. Afr J Med Sci. 2005;34(3):275-9.

8. UNAIDS report on the global AIDS Epidemic. Geneva: UNAIDS, 2012.

9. Obirikorang C, Yeboah FA. Blood hemoglobin measurements as a predictive indicator for the progression of HIV/AIDS in resource-limited setting. J Biomed Sci. 2009; 16:102.

10. Mildvan D, Creagh T, Leitz G. The anemia prevalence study group: Prevalence of anemia and correlation with biomarkers and specific antiretroviral regimens in 9690 human immune deficiency virus infected patients. Curr med res opin. 2007;23(2):343-55

11. Mata-Marín JA, Gaytán-Martínez JE, MartínezMartín RE. Risk factors and correlates for anemia in HIV treatment-naïve infected patients: a crosssectional analytical study. Brit Med Centr Res Not. 2010;3:230.

12. World Health Organization. Nutritional Anemia. World Health Organ. Tch ref ser. 1972;503.

13. Okunade KS, Adegbesan-Omilabu MA. Anemia among pregnant women at the booking clinic of a Teaching Hospital in South-western Nigeria. Int $\mathbf{J}$ of Med Biomed Resea. 2014;3(2):114-20.

14. Lawson RJ. Anemia in pregnancy. In: Lawson JB, Steward (Ed). Obstetrics and Gynecology in Tropics and developing countries. Edward Arnold Publ. 1983:73-9.

15. Harrison KA. Anemia in pregnancy. In: Lawson JB, Harrison KA, Bergsrom S (editors). Maternity Care in Developing countries. Roy Colle Obstet Gynaecol Press. 2000:2-128.

16. Ogunbode O. Anaemiainpregnacy In: Okonofua F, Odunsi $\mathrm{K}(\mathrm{Ed})$. Contemporary Obstetrics and
Gynaecology for Developing countries. Women's Health and Action Research Centre. 2003:515-29.

17. Okeudo C, Ezem BU, Ojiyi EC, Anolue FC, Dike EI. Prevalence of anemia among HIV positive pregnant women at booking in Orlu, South-Eastern Nigeria: Afri Medic J. 2014;5(1):45-9.

18. Olatunbosun OA, Abasiattai AM, Bassey EA, James RS, Ibanga G, Morgan A. Prevalence of anaemia among pregnant women at booking in the University of Uyo Teaching Hospital, Uyo, Nigeria. Bio Med Resea Int. 2014;2014.

19. Adesina O, Oladokun A, Akingbola T, Awolude O, Adewole I. Risk of anemia in HIV positive pregnant women in Ibadan, south west Nigeria. Afr J Med Sci. 2011;40(1):67-73

20. Ohihoin AG, Musa J, Sagay AS, Uja IAO, Herberston EC, Ocheke A. Prevalence and determinants of anemia among HIV positive pregnant women attending ante-natal clinic at Jos University Teaching Hospital, Jos North Central Nigeria: BJM and Med research. 2014;4(34):534856.

21. Idowu OA, Mafiana CF, Sotiloye D. Anemia in pregnancy: A survey of pregnant women in Abeokuta Nigeria. Afr Health Sci. 2005;5(4):295-9.

22. Olusanya O, Okpere E, Ezimokhai M. The importance of social class in fertility control in a developing country. W Afric J Medic. 1985;4:20512.

23. Grztchen A, Gernald I. Msamango, Donna S, Ernest JN, Urassa et al. Nutritional factors and infectious disease contribute to anemia among pregnant women with Human Immuno Deficiency Virus in Tanzania. J Nutrit. 2002;130:19050-57.

24. Ndukwu GU, Dienye PO. Prevalence and sociodemographic factors associated with anaemia in pregnancy in a primary health center in Rivers state, Nigeria. Afr J Prm Heal Car Fam Med. 2012;4(1):17.

25. Ajayi AO, Ajayi EA, Fasakin KA. CD4+ Tlymphocytes cell counts in adults with human immunodeficiency virus infection at the medical department of a tertiary health institution in Nigeria. Ann Afr Med. 2009;8:257-60.

26. Moyle G. Anemia in persons with HIV infection: prognostic marker and contribution to morbidity. AIDS Rev. 2002;4(1):13-20.

27. Willis TS, Nadler JP, Somboowit C, Vincent A, Leitz G, Marino et al. Anemia prevalence and associated risk factors in a single centre ambulatory HIV clinical cohort. Aids read, 2004;14(6):3014-5.

28. Ibrahim A, Yahaya H, Gwarzo MY, Muhammad AB, Sharfadi RS. Anaemia and Immunological Markers in HIV Patients on Antiretroviral Drugs (HAART). O Sci J Clinic Medic. 2015;30(2):42-6.

29. Deresse D, Dereje L, Aderajew A. Prevalence of anemia before and after the initiation of antiretroviral therapy at ART Centre of Hawassa University Referral Hospital, Hawassa, South Ethiopia. Schol J Medic. 2013;3(1):1-6. 
30. Paul AV, Alexandra ML, Douglas D, Donna M, Ronald M, and Michael S. Anemia in HIV Infection: Clinical Impact and Evidence-Based Management Strategies: Anemia in HIV Working Group; the Infectious Diseases Society of America, 2014.
Cite this article as: Eze IO, Innoeze $\mathrm{CU}$, Ayogu ME, Eze SC. Prevalence and determinants of anemia amongst HIV positive pregnant women in a tertiary Hospital in Nigeria. Int J Reprod Contracept Obstet Gynecol 2020;9:4825-33. 